\title{
A Singular Method to Compare Dental Radiographic Films Used to Study Maxillofacial Structures
}

\author{
Un Singular Método Comparativo de Radiografías Dentales Usadas \\ en Estudios de Estructuras Maxilofaciales
}

\begin{abstract}
"Plauto Christopher Aranha Watanabe; ** João Paulo Mardegan Issa; *Luiz Carlos Pardini; "Solange Aparecida Caldeira Monteiro \& *Alma Blásida Concepción Elizaur Benitez Catirse
\end{abstract}

WATANABE, P. C. A.; ISSA, J. P. M.; PARDini, L. C.; MONTEIRO, S. A. C. \& CATIRSE, A. B. C. E. B. A singular method to compare dental radiographic films used to study maxillofacial strutures. Int. J. Morphol., 25(3):573-578, 2007.

SUMMARY: The aim of this article is to present a singular and practical method to compare roentgenograms, concerning optical density and contrast. This method is specifically indicated for research related to stepwedge penetrometer and photodensitometer.

KEYWORDS: Dental radiographic films; Radiographic density; Radiographic contrast.

\section{INTRODUCTION}

When the qualities of dental roentgenograms are evaluated, some parameters are generally considered: a) the radiographic density or the optical density measure of the degree -of film darkening; b) the radiographic contrast or the capacity to sharply distinguish different tones of gray on the same roentgenogram; c) speed or the reciprocal of the exposure required to produce a density of 1.0 above base-plus-fog; d) resolution of the exposure settings available on the X-ray unit, which limits the density value obtained on the line-pair plate images (Fuchs, 1971).

The comparison between radiographic densities seems to be an easy task to perform measuring the optical density at the darkest site of the roentgenogram with photodensitometer, but the density is measured by the ability of the developed silver in the piece of film to stop light from passing through. The darkest sites are always the areas where the X-rays reach the film directly (zero scale), with no obstacle interposed between the source of radiation and the surface of the film.

On the other hand, the contrast is more complex. The contrast is critical for distinguishing objects in a radiographic film. Contrast in a dental $\mathrm{x}$-ray image is influenced by three factors: subject contrast, film contrast and processing. In fact, when the radiographic contrast is studied, an aluminum penetrometer, it is commonly used to record the range of different tones of gray produced by the progressive thickness or height of the stepwedge aluminum penetrometer on the same exposed film, subject contrast (Manson-Hing and Bloxon, 1985). The scale of resultant gray tones, which may range from white to black on the radiograph is used to evaluate sharpness to distinguish several hues of gray, principally between adjacent steps of the penetrometer.

When the contrast between roentgenograms are compared, many difficulties may arise, if one considers that the measures of the optical density at the radiographic bands (relative to the various steps of the penetrometer) are not mutually independent, when it is used a aluminum stepwedge, the decreasing thickness of the steps produces a multiplicative effect on the progressively darker hue of the images of the aluminum steps on the roentgenogram. This fact may cause considerable difficulty in the statistical analysis of the experimental results, and based in this concept, the present method was developed, to compare the diagnostic quality by means of the radiographic density and contrast using a single mathematics transformation of the original data of densities.

\footnotetext{
* Professor, Faculty of Dentistry of Ribeirão Preto, University of São Paulo, São Paulo, Brazil.

**Gaduate student, Faculty of Dentistry of Ribeirão Preto, University of São Paulo, São Paulo, Brazil.
} 


\section{MATERIAL AND METHOD}

This method initially outline in a previous papers (Maia-Campos \& Tamburus, 1991; Watanabe et al., 1994) and it was subsequently improved to permit the simultaneous setting of the characteristic optical density and contrast of a roentgenogram, having in view of the unique mathematical transformation.

A comparison between Kodak intrabucal films $D$ and E are employed here, only with the objective to illustrate the several steps of this method.

We used non-expired Kodak periapical films (31 x $41 \mathrm{~mm}$, ANSI 1.2), eight of them belonging to the D sensitivity group (Ultra-speed) and eight to the E sensitivity group (E-speed). Before the experiments, the films were stored in environment cooled temperature $10^{\circ} \mathrm{C}$, during 20 minutes, before the exposure. Radiographs of an aluminum stepwedge (Watanabe et al., 1989) were obtained, standard on the mandible molar region according to the instructions of the "Catalogue and reference guide of Kodak dental products" in the Kodak Internet homepage (Table I and Fig. 1).

After exposure, sixteen periapical films were submitted to manual radiographic processing using fresh Kodak chemicals according to manufacturer instructions and the temperature/time method. The films were developed for 2 and 112 minutes in solutions maintained at $25^{\circ} \mathrm{C}\left(77^{\circ} \mathrm{F}\right)$ in a darkroom, which was also devoid of safety light. The remaining procedures for radiographic processing also carried out according to manufacturer instructions.

The films were then dried in an incubator with circulating hot air. The radiographs, which had been identified with lead letters before radiographic exposure, were mounted on cards for photodensitometric reading with a digital densitometer II, model 0.7-424 (Victoreen, Inc.) with a diaphragm aperture of $1 \mathrm{~mm}$. The 144 values obtained were recorded on appropriate cards and represented the experimental sample. These original data referred to the two experimental groups, i.e., D group and E-speed group.

Table I. Mean original values of the readings of the exposure factors obtained with the NERO apparatus.

\begin{tabular}{cccc}
\hline & & EXPOSURE FACTORS \\
SENSITIVITY GROUPS & KVp (Effective) & Time (Seconds) & Radiation dose (mR) \\
\hline D (DF-58) & 70.6 & 0.802 & 53.3 \\
E (SPEED) & 71.3 & 0.407 & 23.1 \\
\hline
\end{tabular}
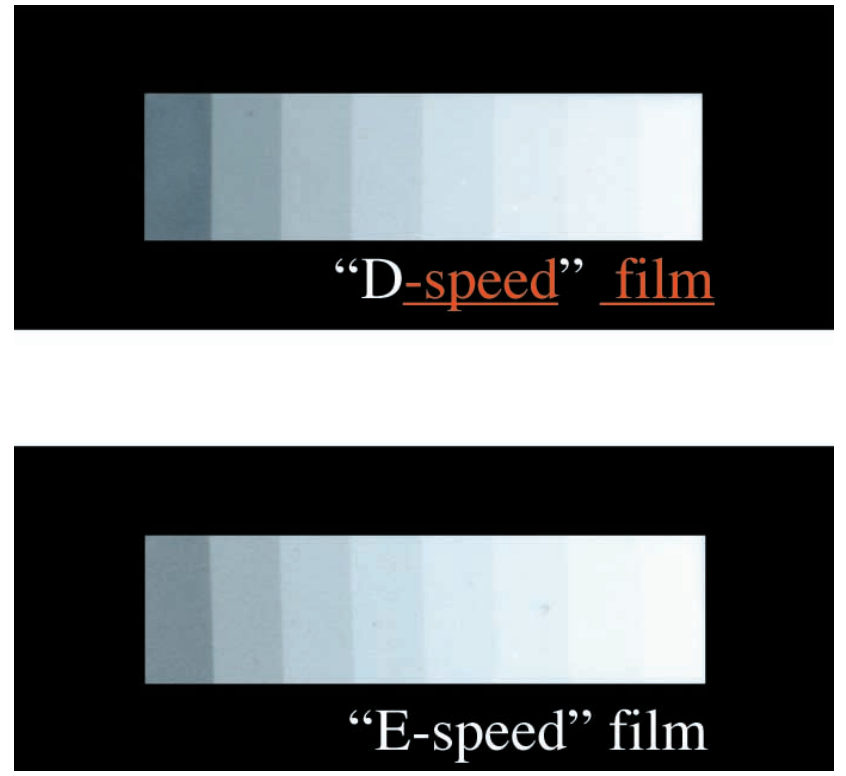

Fig. 1. Radiographic films penetrometer.

\section{RESULTS}

The densitometric readings of the stepwedge images are independent data. Furthermore, these data were cumulative since the thickness of each step increased according to a constant additive factor in relation to the previous step. On this basis, the nature of these data required a more adequate statistical analysis for the correct interpretation of the responses (Maia-Campos \& Tamburus; Watanabe et al., 1994).

Data presented on Table II, present the means and standard deviations (+ SD) of the original data (radiographic density) and the Fig. 2 the densitometric curves. The first step was able to apply a regression test for multiple curves, in order to verify which geometric model better fitted the experimental data. The hyperbolic equations gave excellent "r" values, indicating concordance between the experimental dates and the derived equations. 
The results on Table III show the best fitting curve and it was the $2^{\text {nd }}$ order hyperbola, whose mathematical equation can be thus expressed: $y=(a+b x)-2$. These data were submitted to hyperbolic transformation for eight replications of the experimental groups for each thickness of the aluminum stepwedge (Table IV). A simple algebraic transformation leads to this mathematical equation: $y-1 / 2=$ $a+b x$. Thus, the hyperbolic transformation of the original data produces an oblique straight line, which it is a very advantageous fact (Fig. 3).

Hyperbolic transformation of the original data transforms the original hyperbolic curve into a straight line fitted by the equation $y=a+b x$, which permits a much easier interpretation of the radiographic quality of the images (Maia-Campos \& Tamburus; Watanabe et al., 1989).

When the original values for the two film groups were submitted to normality tests they showed non-normal distribution, the same situation occurred for the "a" and " $b$ " values obtained fromthe equation of the regression line for each replication. Table $\mathrm{V}$ shows intergroup comparison of the means and standard deviation (+ SD) values of radiographic density (a) and contrast (b). The MannWhitney $U$ test indicated statistical difference $(p<0.01)$ between Ultra-speed and E-speed for both conditions, with E-speed being less dense and showing less contrast than Ultra-speed.

Table II. Mean (+ SD) values of the optic densities of the original values for the D and E-speed groups, for 8 replications per group.

\begin{tabular}{ccccccccccc}
\hline & \multicolumn{8}{c}{$\begin{array}{c}\text { Mean optical densities } \\
\text { Thickness of the aluminum stepwedge (mm) }\end{array}$} \\
\hline groups & 0 & 2 & 4 & 6 & 8 & 10 & 12 & 14 & 16 \\
O.V. & 2.28 & 1.72 & 1.33 & 1.05 & 0.85 & 0.71 & 0.60 & 0.52 & 0.44 \\
O.V. & 1.87 & 1.41 & 1.07 & 0.86 & 0.72 & 0.61 & 0.53 & 0.47 & 0.41 \\
\hline
\end{tabular}

O.V. - original values

Fig. 2. Regression lines for groups D and E-speed without hyperbolic transformation of the data.

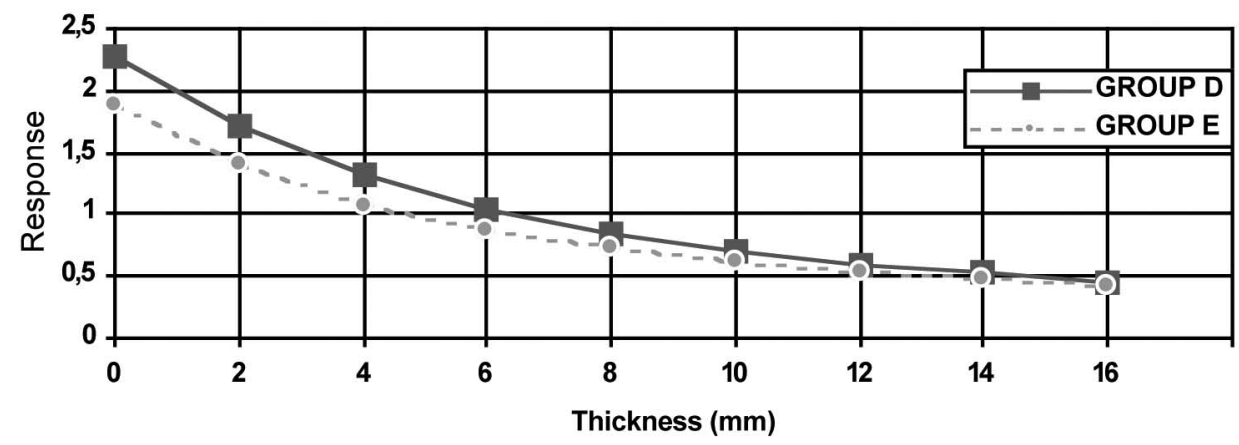

Table III. Regression lines for the curves tested.

\begin{tabular}{llccc}
\hline CURVE & EQUATION & "a” & "b" & "r" \\
\hline Straight line & $\mathrm{Y}=\mathrm{a}+\mathrm{bx}$ & 1.7278 & -0.0948 & -0.9203 \\
Power b of $\mathrm{x}$ & $\mathrm{Y}=\mathrm{a} \cdot \mathrm{x}^{\mathrm{b}}$ & 0.9734 & -0.1364 & -0.7655 \\
Exponential & $\mathrm{Y}=\mathrm{a} \cdot \mathrm{e}^{\mathrm{bx}}$ & 1.8377 & -0.0969 & -0.9778 \\
Logarithmic & $\mathrm{Y}=\mathrm{a}+\log (\mathrm{x})$ & 1.1325 & -0.1587 & -0.8575 \\
Parabola & $\mathrm{Y}=\mathrm{a}+\mathrm{bx})^{2}$ & 1.3270 & -0.0470 & -0.9548 \\
Power $\mathrm{x}$ of b & $\mathrm{Y}=\mathrm{a} \cdot \mathrm{b}^{\mathrm{x}}$ & 1.8377 & 0.9076 & -0.9778 \\
Hyperbola $1^{\text {st }}$ order & $\mathrm{Y}=1 /(\mathrm{a}+\mathrm{bx})$ & 0.4030 & 0.1163 & 0.9845 \\
Hyperbola $2^{\text {st }}$ order & $\mathrm{Y}=1 /(\mathrm{a}+\mathrm{bx})^{2}$ & 0.7053 & 0.0521 & 0.9875 \\
\hline
\end{tabular}


WATANABE, P. C. A.; ISSA, J. P. M.; PARDINI, L. C.; MONTEIRO, S.A. C. \& CATIRSE, A. B. C. E. B. A singular method to compare dental radiographic films used to study maxillofacial strutures. Int. J. Morphol., 25(3):573-578, 2007.

Table IV. Mean (+ SD) values of the optic densities of the original values submitted to hyperbolic transformation for the D and E groups, for 8 replications per group.

\section{Mean optical densities}

Thickness of the aluminum stepwedge(mm)

\begin{tabular}{lcccccccccc}
\hline groups & 0 & 2 & 4 & 6 & 8 & 10 & 12 & 14 & 16 \\
V.H.T. & 0.66 & 0.76 & 0.86 & 0.97 & 1.08 & 1.18 & 1.29 & 1.38 & 1.50 \\
V.H.T. & 0.73 & 0.84 & 0.96 & 1.07 & 1.17 & 1.28 & 1.37 & 1.46 & 1.55 \\
\hline
\end{tabular}

V.H.T. - values submitted to hyperbolic transformation

Table V. Mean (+ SD) values of radiographic density ("a") and contrast ("b") for the experimental groups D and E-speed.

\begin{tabular}{cccc}
\hline \multicolumn{2}{c}{ "a" Values - Radiographic } & Density* & \multicolumn{2}{c}{ "b" Values - Radiographic Contrast* } \\
\hline Group D & Group E & Group D & Group E \\
(ULTRA-SPEED) & (E SPEED) & (ULTRA-SPEED) & (E-SPEED) \\
0.6567 & 0.76183 & 0.05254 & 0.05103 \\
\pm 0.01 & \pm 0.01 & \pm 0.00 & \pm 0.00 \\
\hline
\end{tabular}

*The Mann-Whitney U test indicated a significant difference $(\mathrm{p}<0.01)$

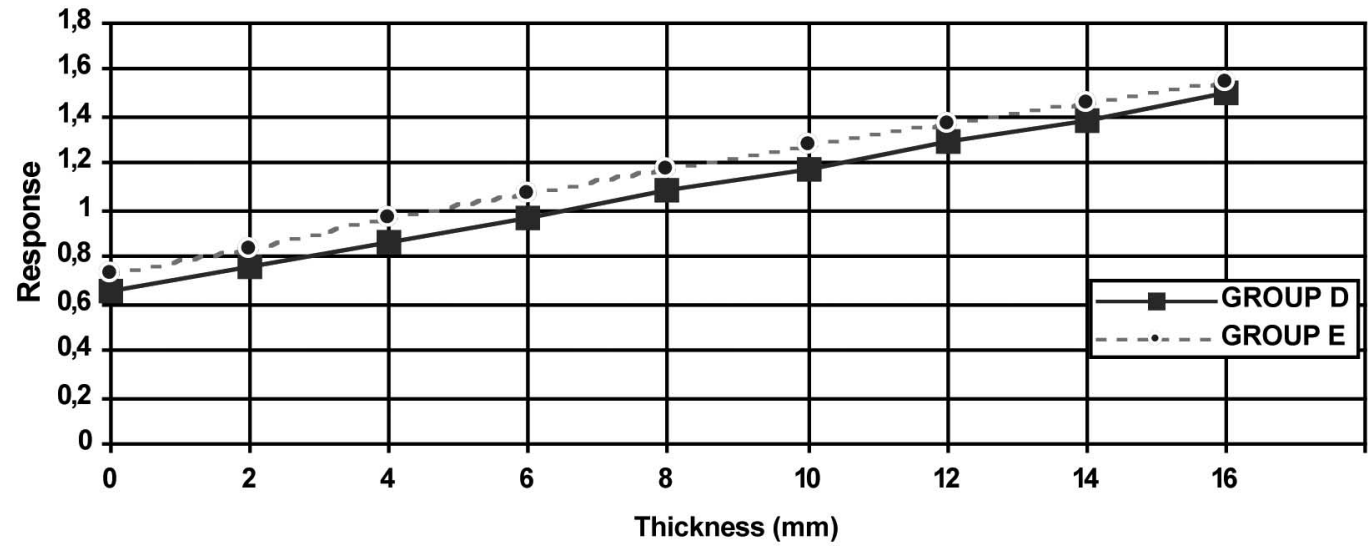

Fig. 3. Regression lines for groups D and E-speed with hyperbolic transformation of the data

\section{DISCUSSION}

Dental radiography is the major auxiliary tool for diagnostic examination used by dental surgeons with the objective to elucidate and prevent some pathologies of the maxillomandibular complex. The ideal radiograph should illustrate with accuracy the radiographic structures, with a size as close as possible to reality, having an appropriate density and contrast for this type of examination, and expose the patient to the least possible amount of radiation, according to the principles of Alara (Gelskey \& Baker, 1984), even the low doses of radiation used in dental procedures may be harmful (Watanabe et al., 1989).

The major objective of the manufacturer of E-speed film was to produce a film with the same radiographic image quality as Ultra-speed but with the maintenance of the reduced dose of exposure obtained with E-speed film. Our 
results demonstrated that it was possible to observe statistical difference between the D and E-speed groups, both in terms of density and contrast about this method. Table III should be interpreted in an inverse manner due to the hyperbolic transformation of the original data.

When we evaluated the results without considering the exposure values (zero), which were the values presenting the highest standard deviation, we also have statistical difference $(\mathrm{p}<0.01)$ for both density and contrast. The use of these values is recommended by Oishi and Parfitt (1976), who stated that these direct exposure values are of the utmost importance for radiographic interpretation.

With the objective to perform a mathematic transformation, by the better correlation values, it is used a computational program that can takes the original values previously saved in a data file and directly transforms them according to the mathematical relation already mentioned $\left(\mathrm{Yi}^{\prime}=(\mathrm{yi})-1 / 2\right)$.

By using the same computer software, the step thickness of the penetrometer (xi) was paired with its corresponding value of optical density (yi'), and the pairs were submitted to the linear regression test (one test for each roentgenogram).

The values of "a" and "b" of the regression lines were used to elaborate Table V, which list the data concerning contrast and optical density parameters, respectively, relative to all the roentgenograms in the study. The following steps of the statistical analysis depend primarily on the data distribution, and secondarily on the individual preferences of each investigator.

Therefore, there are several advantages of using this method to analyze, compare, evaluate and interpret the results obtained when a stepwedge penetrometer is used to study roentgenograms. The multiple numerical values resulting from the measure of the optical density at each step of the penetrometer on a radiography are reduced for two values, the tangent of the slope angle, which represents the contrast parameter to that specific roentgenogram, and the point where the regression line intersects the axis of ordinates, which represents the general optical density of the same roentgenogram. This fact makes statistical analysis of the experimental data easier.

These two parameters, contrast and optical density, are mathematically linked to one another by the equation of the straight regression line. For this reason, this option seems to be better than arbitrarily selecting the optical density of the steps in a penetrometer, with the objective to compare the optical densities between roentgenograms.

The statistical tests used to process the experimental data are routine tests and the choice of the statistical test depends on the data themselves, mainly on their distribution, homogeneity and independence.

The original data indicated the fraction of the total transmitted light that is absorbed when it passes through the roentgenogram. An important detail to keep in mind, however, is that the hyperbolic transformation is an inverse operation. In consequence, after this transformation, when the inverse of the absorbed light is taken as the new value for the original datum, it is necessary to speak thereafter in terms of transmittance, and the results must be interpreted according to this new point of view.

The ISO method is rotinously used for determining the contrast of intraoral films, by the International Organization for Standardization and others. Price (1995) discussed the limitations of these methods when compared dental films. The contrast determined according to ISO standards or other methods suggested by Boere and van Aken (1990), using only two optical densities (D2 and D1) on the characteristic curve divided by the difference between the log relative exposures (E2 and E1) that caused these densities, ignores the response between and above these values (Yakoumakis et al., 2001; Zlataric et al., 2002; Bernstein et al., 2003).

In conclusion, we can infer that it is possible to use this single method to compare the quality of radiographic films.

WATANABE, P. C. A.; ISSA, J. P. M.; PARDINI, L. C.; MONTEIRO, S. A. C. \&CATIRSE, A. B. C. E. B. Un singular método comparativo de radiografías dentales usadas en estudios de estructuras. Int. J. Morphol., 25(3):573-578, 2007.

RESUMEN: El objetivo de este artículo es presentar un método singular y práctico para comparar roentgenogramas, referentes a la densidad óptica y al contraste. Este método se indica específicamente para la investigación con el penetrómetro stepwedge y el fotodensitómetro.

PALABRAS CLAVE: Películas radiográficas odontológicas; Densidad radiográfica; Contraste radiográfico. 


\section{REFERENCES}

Bernstein, D. I.; Clark, S. J.; Scheetz, J. P.; Farman, A. G. \& Rosenson, B. Perceived quality of radiographic images after rapid processing of D- and F-speed direct-exposure intraoral x-ray films. Oral Surg. Oral Med. Oral Pathol. Oral Radiol. Endod., 96:486-91, 2003.

Boere, G \& van Aken, J. Densitometric properties of direct exposure dental X-ray films in relation to the characteristic curve. Dentomaxillofac. Radiol., 19:49-54, 1990.

Fuchs, A.W. Principles of radiographic exposure and processing. $2^{\text {nd }}$ ed. CC Thomas: Illinois, 1971.

Gelskey, D. E. \& Baker, C.G. The ALARA concept. Population exposure from X-ray in dentistry - as low as reasonably achievable. J. Can. Dent. Assoc., 50:402-3, 1984.

Maia-Campos, G. \& Tamburus, J.R. A method to evaluate and compare roentgenograms. Braz. Dent J., 2:95-102, 1991.

Manson-Hing, L. R. \& Bloxon, R.M. A stepwedge quality assurance test for machine and processor in dental radiography. J. Am. Dent. Assoc., 110:910-3, 1985.

Oishi, T.T. \& Parfitt, G. J. Effects of varying peak kilovoltage and filtration on diagnostic dental radiographs. J. Can. Dent. Assoc., 42:449-52, 1976.

Price, C. Densitometric evaluation of a new E-speed dental radiographic film. Dentomaxillofac. Radiol., 24:30-6, 1995.
Watanabe, P. C. A.; Boscolo, F. N.; Vizioli, M. R. Efeitos de baixas doses de radiação sobre a gênese e evolução do tecido de granulação. Rev. Odontol. Univ. São Paulo, 8:137-43, 1994.

Watanabe, P. C.A.; Tamburus, J. R. \& Maia-Campos, G. Influência da temperatura ambiental de armazenagem sobre a densidade e contraste radiográficos de filmes vencidos e não-vencidos. Rev. Odontol. Univ. São Paulo, 3:420-6, 1989.

Yakoumakis, E. N.; Tierris, C. E.; Stefanou, E.P.; Phanourakis, I. G. \& Proukakis, C.C. Image quality assessment and radiation doses in intraoral radiography. Oral Surg. Oral Med. Oral Pathol. Oral Radiol. Endod., 91:362-8, 2001.

Zlataric, D. K.; Celebic, A.; Milat, O. \& Papic, M. A method to evaluate and compare two different intraoral radiographs of the same patient. Coll. Antropol., 26:65766, 2002.

Correspondence to:

Dr. Plauto C. A. Watanabe

Departamento de Morfologia, Estomatologia e Fisiologia Faculdade de Odontologia de Ribeirão Preto, USP

Avenida do Café s/n, 14040-904

Ribeirão Preto, SP

BRASIL

Email: watanabe@forp.usp.br

Received: 21-03-2007

Accepted: 16-06-2007 